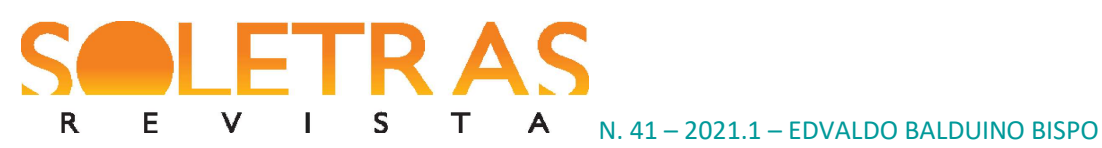

ALINE PRISCILLA ALBUQUERQUE BRAGA

\title{
Propriedades funcionais da relativa livre introduzida por quem
}

\author{
Edvaldo Balduino Bispo ${ }^{1}$ \\ Aline Priscilla Albuquerque Braga ${ }^{2}$
}

\begin{abstract}
Resumo: Neste artigo, investigamos aspectos funcionais (semânticos, semântico-cognitivo e sociointeracionais) implicados no uso da oração relativa livre introduzida por quem no Português Brasileiro (PB). Fundamentamo-nos teoricamente na Linguística Funcional, conforme Givón (1984, 1995), Martelotta (2011), Furtado da Cunha e Bispo (2013), Furtado da Cunha, Oliveira e Martelotta (2015). Trata-se de uma pesquisa quali-quantitativa de natureza interpretativista. Utilizamos como fonte de dados empíricos anúncios de jornal e cartas particulares produzidos no século XIX, provenientes da plataforma de corpora do projeto História do Português Brasileiro (PHPB). Os resultados indiciam que (i) o pronome quem aponta para um referente caraterizado pelos traços semânticos [+ANIMADO], [+HUMANO], [+/-DEFINIDO] e [+/-GENÉRICO]; (ii) não há restrição quanto aos tipos semânticos de verbo que podem predicar a relativa livre e a oração em que ela se encaixa; (iii) o quem pode exercer uma variedade de papéis semânticos; (iv) questões de natureza sociointeracional, a exemplo de subjetividade, intersubjetividade e inferência pragmática, motivam o uso da relativa livre nos dados analisados.
\end{abstract}

Palavras-chave: Aspectos funcionais. Oração relativa livre. Linguística Funcional.

\section{Considerações iniciais}

As orações relativas são definidas na literatura linguística como um tipo de oração subordinada que, sintaticamente, se caracterizam como estruturas modificadoras de um núcleo nominal. Em seus estudos, Keenan (1985) afirma que existem dois tipos de orações relativas, condicionados à presença ou à ausência de um Sintagma Nominal (doravante, SN) ao qual a relativa se vincula. Quando elas apresentam o SN expresso, são denominadas relativas com antecedente; quando não exibem esse SN ou o exibem dentro da relativa, são consideradas relativas sem antecedente. Para exemplificar essa distinção, atentemos para os dados em (1), (2) e (3).

\footnotetext{
${ }^{1}$ Mestre (2003) e Doutor (2009) em Estudos da Linguagem pela UFRN. Atualmente, é Professor Associado da Universidade Federal do Rio Grande do Norte, Câmpus de Natal, onde atua nas áreas de Língua Portuguesa, na graduação, e de Linguística, na pós-graduação. Rio Grande do Norte, Brasil. E-mail: edbbispo@gmail.com. ORCID iD: 0000-0002-5607-3407

${ }^{2}$ Mestra em Estudos da Linguagem pela Universidade Federal do Rio Grande do Norte. Doutoranda pelo mesmo Programa. Professora da Rede Estadual de Ensino do Rio Grande do Norte. Rio Grande do Norte, Brasil. E-mail: alinepalbuquerquebraga@gmail.com. ORCID iD: 0000-0003-0813-0515
} 


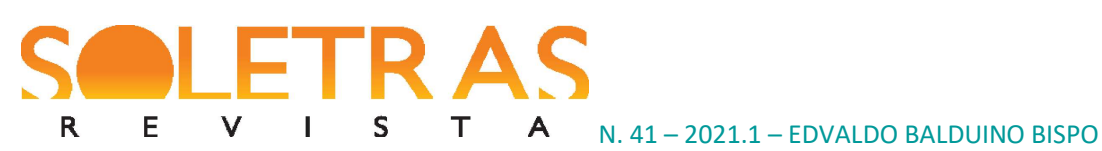

ALINE PRISCILLA ALBUQUERQUE BRAGA

(1) A sua carta de 6 do mes proximo passado me deo grande saptisfação [...] de ter| achado com saúde toda a sua Familia, á quem| rendo os meus respeitos, que igualmente são derigi $=\mid$ dos por minha mulher [...] (Corpus PHPB, carta particular, século XIX)

(2) Quem quizer aprender a traduzir e fallar as Línguas Franceza e Ingleza, dirija-se a Diogo Antonio Archer (Portuguez [...] (Corpus PHPB, anúncio, século XIX)

(3) Remeto-lhe sua Burra que condusio o Vigario, porem que aqui estava intregue ao Rodrigues que tinha fugido e foi pega-do no Bucarú, aquém vier aparte d'elle direi o ocorrido [...] (Corpus PHPB, carta particular, século XIX)

A oração destacada em (1) ilustra um caso de oração relativa com antecedente (toda $a$ sua Família), ao passo que as exemplificadas em (2) e em (3) correspondem a relativas sem antecedente, visto que não há SN a que essas orações se vinculem.

Tomada como um universal linguístico, segundo apontam Bispo (2009), Bispo e Furtado da Cunha (2019), a oração relativa tem sido investigada por muitos estudiosos e em diferentes perspectivas, conforme mostram Bispo e Oliveira (2014) e Bispo (2018). As relativas sem antecedente, foco deste artigo, são também denominadas relativas livres na literatura linguística e têm sido investigadas principalmente por pesquisadores gerativistas. É o caso de Brito (1988), Móia (1992), Medeiros Junior (2005; 2014) e Marchesan (2008; 2012) - no que concerne, primordialmente, à descrição de aspectos da constituição sintática desse tipo oracional e, em menor grau, à explicitação de suas propriedades semânticas.

Braga (2018) e Bispo (2020) investigaram as relativas sem antecedente à luz do funcionalismo linguístico. No primeiro trabalho, a autora trata de características formais (morfossintáticas) e de aspectos semânticos, discursivos, pragmáticos e cognitivos envolvidos em ocorrências da relativa livre introduzida por quem. No segundo, o pesquisador discute, em uma abordagem funcional-construcionista, relativas sem antecedente introduzidas por quem em adágios populares do tipo quem cala consente, quem desdenha quer comprar.

Dito isso, este artigo representa o desdobramento da pesquisa realizada por Braga (2018). Em linhas gerais, objetivamos analisar aspectos funcionais - mais precisamente, semânticos e discursivo-pragmáticos - implicados em instâncias de uso da relativa livre introduzida por quem. De modo específico, pretendemos (i) caracterizar os traços semânticos do referente para o qual o pronome quem aponta, (ii) atestar os tipos semânticos de verbos 


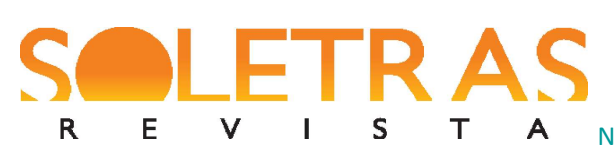

$\begin{array}{llllllll}\mathbf{R} & \mathbf{E} & \mathbf{V} & \mathbf{I} & \mathbf{S} & \mathbf{T} & \mathbf{A} & \mathrm{N} .41-2021.1-\text { EDVALDO BALDUINO BISPO }\end{array}$

presentes na relativa livre e na oração em que ela se encaixa, (iii) verificar os papéis semânticos atribuídos ao pronome quem tanto pelo predicador da relativa livre quanto pelo da oração matriz, (iv) explicitar a atuação de processos sociointeracionais nas ocorrências da oração sob enfoque.

Sustentamos nossa discussão em pressupostos da Linguística Funcional, conforme Givón (1984, 1995), Furtado da Cunha e Bispo (2013), Furtado da Cunha, Oliveira e Martelotta (2015), entre outros. Os dados desta pesquisa compõem-se de textos extraídos do conjunto de corpora do projeto História do Português Brasileiro (daqui em diante, PHPB), especificamente anúncios de jornal e cartas particulares que circularam no Brasil ao longo do século XIX.

Além da introdução e da conclusão, organizamos este artigo em cinco seções. $\mathrm{Na}$ próxima, apresentamos a perspectiva teórica que fundamenta esta pesquisa. Na terceira seção, explicitamos os aspectos metodológicos do trabalho. Em seguida, discutimos fatores semânticos e semântico-cognitivo relacionados aos usos da relativa livre introduzida por quem. Na penúltima seção, tratamos de questões sociointeracionais envolvidas em instâncias desse tipo oracional.

\section{Linguística Funcional}

Fundamenta a discussão aqui empreendida a Linguística Funcional de vertente norteamericana, nos termos de Givón (1979, 1984, 1995), Thompson e Couper-Kuhlen (2005), Martelotta (2011), Furtado da Cunha, Oliveira e Martelotta (2015), entre outros. Conforme Furtado da Cunha e Bispo (2013), para essa vertente teórica, a configuração gramatical de uma língua é estreitamente relacionada e moldada por fatores cognitivos, semânticos, pragmáticos e discursivos, que atuam em conjunto. Assim, a estrutura linguística emerge do uso, das práticas interacionais situadas.

Nesse contexto teórico, a língua é tomada como uma estrutura maleável, governada pelo uso que dela fazemos em situações reais de comunicação. A gramática de uma língua natural, por sua vez, consiste de um conjunto de padrões regulares e de formas em processo de regularização, decorrentes da sedimentação de rotinas comunicativas e sensíveis a 


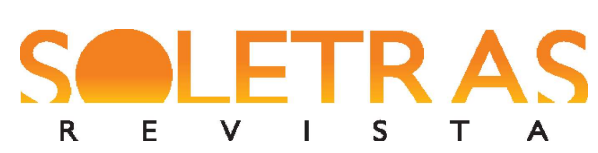

$\begin{array}{llllllll}\mathbf{R} & \mathbf{E} & \mathbf{V} & \mathbf{I} & \mathbf{S} & \mathbf{T} & \mathbf{A} & \mathrm{N} .41-2021.1 \text {-EDVALDO BALDUINO BISPO }\end{array}$

demandas internas e externas ao sistema linguístico (MARTELOTTA, 2011). Resulta desse entendimento que o estudo dos fenômenos linguísticos deve levar em conta o lócus em que eles efetivamente se dão, o que inclui todos os fatores que os contingenciam. É preciso, pois, lidar com dados de fala, escrita e/ou multimodais para melhor explicar tais fenômenos (FURTADO DA CUNHA; BISPO; SILVA, 2013).

Para análise dos dados empíricos aqui considerados, valemo-nos dos seguintes fatores: i) semânticos (tipos semânticos de verbos; traços semânticos dos nomes; papéis semânticos dos nomes); ii) semântico-cognitivo (princípio de iconicidade); iii) sociointeracionais (inter/subjetividade, inferência sugerida, polidez e preservação das faces).

Quanto à classificação semântica dos verbos que ocorrem como predicador da relativa livre e da oração em que ela se encaixa, consideramos a proposta de Borba (1996, 2002), inspirada em Chafe (1979) e sintetizada no quadro a seguir.

Quadro 1 - Classificação dos verbos por tipo semântico

\begin{tabular}{|l|l|}
\hline \multicolumn{1}{|c|}{$\begin{array}{c}\text { TIPO DE } \\
\text { VERBO }\end{array}$} & \multicolumn{1}{c|}{ DEFINIÇÃO } \\
\hline Ação & $\begin{array}{l}\text { Indica um fazer por parte do sujeito, isto é, uma ação. } \\
\text { Ex.: A velha gritava desaforos. }\end{array}$ \\
\hline Processo & $\begin{array}{l}\text { Exprime um acontecer (algo pelo qual o sujeito passa) ou um } \\
\text { experimentar (algo que ele experimenta). } \\
\text { Ex.: O bebê acordou. }\end{array}$ \\
\hline Ação-processo & $\begin{array}{l}\text { Expressa uma ação que atinge um complemento, provocando uma } \\
\text { mudança ou promove a existência de algo. } \\
\text { Ex.: José quebrou o pires. }\end{array}$ \\
\hline Estado & $\begin{array}{l}\text { Expressa uma propriedade (estado, condição, situação) localizada } \\
\text { no sujeito. } \\
\text { Ex.: Marinésio tem três filhos. }\end{array}$ \\
\hline
\end{tabular}

Fonte: Adaptado de Borba (1996)

Para atestar os traços semânticos do quem, introdutor da relativa livre, levamos em conta, em nossa análise, as propriedades semânticas dos nomes conforme descritas em Chafe (1979) e resumidas no quadro 2. 


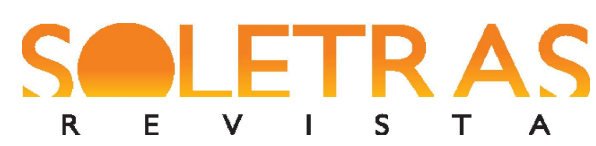

N. 41 - 2021.1 - EDVALDO BALDUINO BISPO

ALINE PRISCILLA ALBUQUERQUE BRAGA

Quadro 2 - Propriedades semânticas dos nomes

\begin{tabular}{|l|l|}
\hline \multicolumn{1}{|c|}{$\begin{array}{c}\text { TIPO DE } \\
\text { NOME }\end{array}$} & \multicolumn{1}{c|}{ DEFINIÇÃO } \\
\hline Animado & $\begin{array}{l}\text { Concebido pelo falante como pertencente à categoria dos animais. } \\
\text { Ex.: Eu assustei o elefante. }\end{array}$ \\
\hline Humano & $\begin{array}{l}\text { Algo que diz respeito apenas a seres humanos. } \\
\text { Ex.: Eu assustei o elefante. }\end{array}$ \\
\hline Definido & $\begin{array}{l}\text { Algo de cuja identidade o falante supõe o conhecimento prévio por } \\
\text { parte do ouvinte ou dele mesmo. } \\
\text { Ex.: A água escorreu no chão. }\end{array}$ \\
\hline Genérico & $\begin{array}{l}\text { Algo que se refere a uma classe inteira de itens e não a um único } \\
\text { membro da classe. } \\
\text { Ex.: Esquilos gostam de amendoim. }\end{array}$ \\
\hline
\end{tabular}

Fonte: Adaptado de Chafe (1979)

Os papéis semânticos, de acordo com Cançado (2005), correspondem às propriedades semânticas que são atribuídas aos argumentos a partir das relações estabelecidas entre os termos da proposição em que eles se encontram. Para este artigo, consideramos duas propostas de classificação para os papéis semânticos dos nomes: a de Borba $(1996,2002)$ e a de Fillmore (1971 apud CASTILHO, 2012), conforme expostas nos quadros 3 e 4, respectivamente.

Quadro 3 - Papéis semânticos segundo Borba (1996, 2002)

\begin{tabular}{|c|c|}
\hline $\begin{array}{l}\text { PAPÉIS } \\
\text { SEMÂNTICOS }\end{array}$ & DEFINIÇÃO \\
\hline Agente & $\begin{array}{l}\text { Aquele que, por si mesmo, desencadeia uma atividade, física ou } \\
\text { não, sendo a origem dela e seu controlador. } \\
\text { Ex.: A estudante quebrou o vaso. }\end{array}$ \\
\hline Paciente & $\begin{array}{l}\text { Aquele que é afetado ou efetuado pela ação verbal. } \\
\text { Ex.: Os animais morreram. }\end{array}$ \\
\hline Experimentador & $\begin{array}{l}\text { Aquele que experimenta o que o conteúdo semântico do verbo } \\
\text { da oração expressa. } \\
\text { Ex.: Helena sente frio. }\end{array}$ \\
\hline Beneficiário & $\begin{array}{l}\text { Aquele que é o destinatário de um benefício. } \\
\text { Ex.: Lúcia herdou da tia um gato siamês. }\end{array}$ \\
\hline Suporte & $\begin{array}{l}\text { Aquele que é mero suporte das propriedades. } \\
\text { Ex.: O prefeito eleito tem fazendas em Goiás. }\end{array}$ \\
\hline
\end{tabular}

Fonte: Adaptado de Braga (2018, p. 31) 


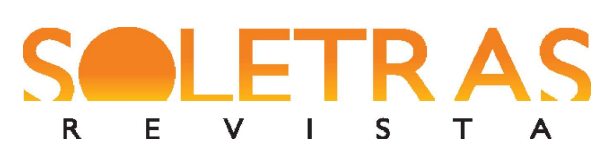

N. 41 - 2021.1 - EDVALDO BALDUINO BISPO

ALINE PRISCILLA ALBUQUERQUE BRAGA

Quadro 4 - Papéis semânticos propostos por Fillmore (1971)

\begin{tabular}{|l|l|}
\hline \multicolumn{1}{|c|}{ PAPÉIS SEMÂNTICOS } & \multicolumn{1}{c|}{ DEFINIÇÃO } \\
\hline Agente & O “instigador" do evento. \\
\hline Contra-agente & Força ou resistência contra a qual a ação é realizada. \\
\hline Objeto & Entidade que se move ou muda. \\
\hline Resultado & Entidade que surge como resultado de uma ação. \\
\hline Instrumento & Estímulo ou causa física do evento. \\
\hline Fonte & Lugar de onde algo se move. \\
\hline Alvo & Lugar para onde algo se move. \\
\hline
\end{tabular}

Fonte: Adaptado de Castilho (2012, p. 255)

O princípio de iconicidade, outro conceito operacional caro a este estudo, diz respeito à correlação motivada entre as estruturas morfossintáticas de uma língua (a forma) e as funções semânticas e pragmáticas que desempenham (conteúdo) (GIVÓN, 1984). Nesse sentido, a estrutura linguística reflete, em alguma medida, a função a que serve nas práticas interacionais.

Evidências translinguísticas demonstram que acréscimos de conteúdo semântico têm correspondência na codificação formal (GIVÓN, 1995; CROFT, 2001). Assim, por exemplo, formas derivadas, que carreiam mais conteúdo que as primitivas, são, em geral, maiores do que estas (seguir > seguinte; julgar $>$ julgamento). Conforme Givón (1984), a iconicidade compreende três subprincípios: quantidade, integração/ proximidade e ordenação. De acordo com o primeiro subprincípio, quanto maior a quantidade de informação, maior a quantidade de material linguístico para codificá-la; ou quanto mais imprevisível (nova) for a informação para o interlocutor, maior será a quantidade de forma a ser utilizada e vice-versa. O subprincípio da proximidade entre os constituintes preceitua que os conceitos mais integrados no plano cognitivo se apresentam com maior grau de ligação morfossintática, conforme se dá com a aposição de afixos ao radical (perto + íssimo = pertíssimo), em que o conteúdo das partes é visto como um todo integrado. Por fim, o princípio da ordenação linear estabelece que os constituintes se ordenam, no tempo e no espaço, segundo pressões cognitivas e/ou comunicativas, em termos de relevância discursiva que se pretende imprimir a uma dada porção da informação ou mesmo em termos de distribuição da informação (velha/dada vs

\footnotetext{
${ }^{3}$ Da fonte de onde a tabela foi retirada, não constam exemplificações dos papéis semânticos propostos por Fillmore (1971). 


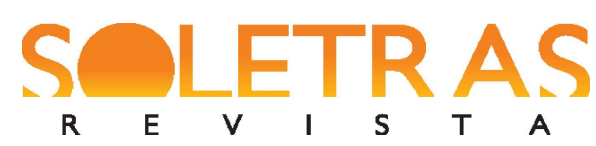

$\begin{array}{llllllll}\mathbf{R} & \mathbf{E} & \mathbf{V} & \mathbf{I} & \mathbf{S} & \mathbf{T} & \mathbf{A} & \mathrm{N} .41-2021.1 \text {-EDVALDO BALDUINO BISPO }\end{array}$

ALINE PRISCILLA ALBUQUERQUE BRAGA

nova). É o que ocorre, por exemplo, em casos de topicalização, como em "Café eu não tomo". Desse modo, a iconicidade é estimulada por questões de clareza e transparência, de forma a reduzir a opacidade entre a forma linguística e seu correlato semântico e/ou pragmático.

De suma relevância para as análises empreendidas sob a ótica da Linguística Funcional são os aspectos sociointeracionais. Neste artigo, utilizamos subjetividade, intersubjetividade, inferência sugerida e estratégias de polidez e preservação das faces.

De acordo com Traugott e Dasher (2002), a subjetividade refere-se à expressão do eu, à representação do ponto de vista do falante em relação a si mesmo, ao outro ou ao próprio dizer. Já a intersubjetividade, conforme os autores, relaciona-se à consideração, pelo falante, de seu interlocutor, seja para agir sobre ele ou para manifestar um julgamento. Envolve estratégias de negociação de sentido, de preservação da face, de monitoramento de ações e reações, de aproximação/ distanciamento entre os parceiros no processo comunicativo (SCHIFFRIN, 1990; BISPO; SILVA, 2013; BISPO; SANTOS, 2019).

Ao interagirem, os falantes criam e negociam significados, amparados no conhecimento que compartilham ou supõem compartilhar com seus interlocutores e nas inferências que podem fazer no ato comunicativo. Trata-se da inferência pragmática, a qual diz respeito ao processo interacional em que o falante, ao utilizar uma dada expressão linguística diferente do convencional, lança uma implicatura e conta com a colaboração do interlocutor para que este, por meio de pistas co(n)textuais, apreenda (ou infira) o significado pretendido. Nos termos de Traugott e Dasher (2002), consiste na reanálise, em significado semântico, de sentidos pragmáticos já convencionalizados.

Consideramos também, nesta investigação, as Estratégias de Polidez e Preservação das Faces. Segundo argumenta Marcuschi (1989), qualquer indivíduo possui dois tipos de face: a positiva e a negativa. Enquanto a primeira concerne à procura pela aceitação de sua personalidade, de seus desejos; a segunda, por sua vez, corresponde à sua proteção, isto é, à liberdade de poder agir independentemente do que o outro espera que seja feito.

De acordo com Goffman (1973), durante uma interação, alguns atos de fala - a exemplo de ordens e pedidos - podem constituir-se como uma ameaça à face positiva que os falantes buscam preservar. Para protegerem a própria face e/ou a de seu(s) interlocutor(es), os participantes de um ato comunicativo, a partir de suas escolhas linguísticas, fazem uso de mecanismos de polidez e preservação da face para garantir uma boa comunicação. 


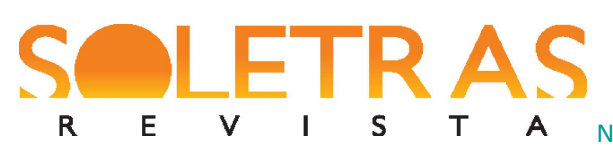

$\begin{array}{llllllll}\mathbf{R} & \mathbf{E} & \mathbf{V} & \mathbf{I} & \mathbf{S} & \mathbf{T} & \mathbf{A} & \mathrm{N} .41-2021.1 \text {-EDVALDO BALDUINO BISPO }\end{array}$

Essas noções serão relevantes para verificar se a configuração estrutural de algumas ocorrências da relativa livre introduzida por quem e a recorrência a elas podem ser uma estratégia para que o escrevente seja polido com o seu interlocutor e, consequentemente, tenha a sua face (ou a de ambos) resguardada durante a comunicação.

\section{Aspectos metodológicos}

Considerando a tipologia da pesquisa, adotamos uma abordagem eminentemente qualitativo-explicativa com suporte quantitativo-descritivo (SILVA, 2004; LAKATOS; MARCONI, 2010). Utilizamos, portanto, o método misto, que envolve a combinação de elementos da pesquisa qualitativa e da quantitativa com o propósito de ampliar e aprofundar o conhecimento sobre o fenômeno estudado (JOHNSON; ONWUEGBUZIE; TURNER, 2007; CUNHA LACERDA, 2016). De acordo com Schiffrin (1987), a associação dos dois métodos de pesquisa, ainda que de forma assimétrica, como é o caso, permite ao pesquisador obter um número maior de ocorrências e uma análise adequada da formação e da estrutura de determinados padrões.

A natureza qualitativa da pesquisa diz respeito ao caráter explicativo/ interpretativista do trabalho, no sentido de identificar aspectos semânticos, cognitivos e interacionais implicados em instâncias de relativas livres introduzidas por quem. O viés quantitativo está relacionado à caracterização do objeto de estudo em termos de mensuração das ocorrências e distribuição quanto aos fatores semânticos considerados (tipo semântico de verbo, propriedades semânticas do referente ao qual o pronome quem remete).

O banco de dados utilizado para o empreendimento deste trabalho consiste em um recorte da plataforma de corpora do projeto PHPB. Particularmente, consideramos anúncios de jornal e cartas particulares que representam o PB escrito ao longo do século XIX em cinco estados brasileiros (Bahia, Minas Gerais, Pernambuco, Rio de Janeiro e São Paulo). A escolha por esse conjunto se deveu à disponibilidade de dados na plataforma referida, relativos à primeira e à segunda metades do século. Em termos de volume textual, delimitamos a amostra por número de palavras: 20411 para os anúncios e 20401 para as cartas, o que resultou em 337 amostras do primeiro gênero e 90 do segundo. O levantamento de dados mostrou 319 


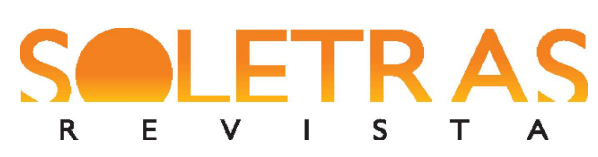

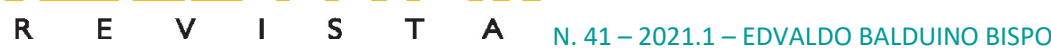

ocorrências da relativa livre introduzida por quem, sendo 281 nos anúncios de jornal e 38 nas cartas particulares.

Após a identificação de todas as ocorrências no corpus, procedemos a um levantamento quantitativo em relação aos seguintes fatores analíticos: (i) traços semânticos do referente para o qual o pronome quem aponta; (ii) tipologia semântica do predicador da relativa livre e da oração matriz; (iii) papel semântico exercido pelo quem em relação ao verbo da relativa e ao verbo da oração principal. Para os demais fatores, os de natureza semântico-cognitiva e sociointeracional, realizamos uma análise meramente qualitativa.

\section{Fatores semânticos e semântico-cognitivo da relativa livre introduzida por quem}

Nesta seção, descrevemos os aspectos de natureza semântica e semântico-cognitiva envolvidos em instâncias da relativa livre introduzida por quem. Para tanto, consideramos os fatores referidos na seção de metodologia.

Em relação aos traços semânticos do referente para o qual o pronome quem aponta, vejamos os dados de (4) a (8).

(4)[...] não declaro oportador desta por. estar aespera dequem sair pri=meiro que mepoça conduzir o cobre (Corpus PHPB, carta particular, século XIX)

(5)[...] Annexa á cadeira de Pharmacia está a offi-|-cina onde se manipulam as preparações. É, par-|ticularmente, para esta que tenho chamado sempre| a attenção de quem póde satisfazerlhe as necessida-|-des. Porém tem sido debalde o clamor de muitos| annos! [...] (Corpus PHPB, carta particular, século XIX)

(6)[...] Quem quizer arrendar um sítio com grande plantação de Café procure a Lidoro Victor Galle para contratar-se pois o mesmo está a mudar-se para o Sertão. (Corpus PHPB, anúncio de jornal, século XIX)

(7)[...] por elle foi encontrado na Ponte da Boa- | vista, huma trouxa de roupa suja: quem | pois, for seu dono, dirija-se a secretaria da | prefeitura, que dando os signaes cerios, lhe | será entregue. || Recife 28 de Novembro de 1840. || Lhiz Francisco Barbalho (Corpus PHPB, anúncio de jornal, século XIX)

(8)[...] Nossos respeitos á Excelentissima Senhora, e| a toda a sua illustre familia, e disponha| como quiser de quem pensa ser com subida| estima e gratidão 


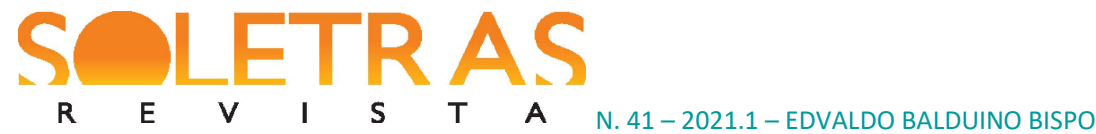

ALINE PRISCILLA ALBUQUERQUE BRAGA

\section{De VossaExcelência| Affectuoso Amigo e Obrigado Colega (Corpus PHPB,} carta particular, século XIX)

A ocorrência destacada em (4) foi retirada de uma carta particular na qual o remetente informa ao destinatário que, caso falte uma parte da quantia de dinheiro que o escrevente lhe mandaria, iria enviá-la em outra oportunidade, quando a primeira tropa que pudesse levá-la saísse. Em um determinado trecho da correspondência, o autor diz que não pode ainda declarar a identidade do portador, "por estar a espera de quem sair primeiro que me possa conduzir o cobre". O uso do quem, nesse dado, faz referência a uma terceira pessoa fora da situação comunicativa, cuja identidade parece ser desconhecida pelos interlocutores. Trata-se, portanto, de uma referência não definida/genérica, conforme Chafe (1979).

A relativa livre em (5) também foi retirada de uma carta pessoal. Consiste em uma correspondência entre um professor de uma faculdade baiana e o encarregado pela confecção das memórias históricas da referida instituição de ensino. Em um trecho da carta, o docente reclama que a faculdade não dispõe de verba suficiente para realizar "preparações" em larga escala e que isso fora informado, havia anos, à pessoa (ou às pessoas) que poderia(m) resolver o problema. Para referir-se a tal(is) pessoa(s), o remetente usa a oração "quem pode satisfazer-lhes as necessidades". Nesse caso, o quem, assim como no dado (4), faz referência a uma terceira pessoa. Contudo, nessa amostra, a identidade dela parece ser de conhecimento do remetente, embora, ao que parece, ele não pretende informá-la ao destinatário. Esse dado representa um uso em que o pronome quem designa um referente semanticamente definido/não genérico.

As ocorrências em (6) e (7) foram retiradas de anúncios de jornal. Nos dois trechos, os anunciantes fazem uso da relativa livre para referir-se aos possíveis leitores dos anúncios, configurando-se como uma referência à segunda pessoa da enunciação. Apesar disso, elas diferem quanto ao referente para o qual o pronome quem aponta: em (6), ele pode remeter a qualquer leitor, assumindo, dessa maneira, um sentido não definido/genérico. Em (7), diferentemente, o quem se refere a um leitor em específico, aquele a quem pertencer o objeto encontrado, possuindo um caráter definido/não genérico.

Por fim, a amostra em (8) foi retirada de uma carta particular endereçada a um amigo. O trecho transcrito representa o final da correspondência, no qual o remetente, ao despedir-se do interlocutor, mostra-se à disposição dele e caracteriza a si mesmo como 


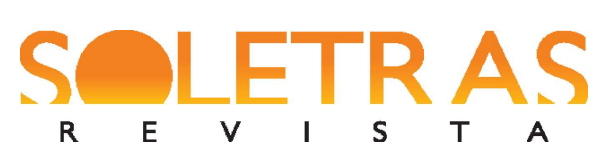

$\begin{array}{llllllll}\mathbf{R} & \mathbf{E} & \mathbf{V} & \mathbf{I} & \mathbf{S} & \mathbf{T} & \mathbf{A} & \mathrm{N} .41-2021.1 \text {-EDVALDO BALDUINO BISPO }\end{array}$

afetuoso amigo e colega agradecido por meio da oração "quem pensa ser com subida estima e gratidão de vossa excelência afetuoso amigo e obrigado colega". Nesse caso, o escrevente usa uma relativa livre para referir-se a si mesmo, isto é, à primeira pessoa da enunciação, conferindo-lhe, portanto, uma acepção apenas aparentemente genérica e não definida, visto que o referente para o qual ela aponta não é qualquer pessoa e não é desconhecido por nenhum dos participantes do ato comunicativo: trata-se do próprio remetente.

Dito isso, é possível concluir que, com base na proposta de Chafe (1979) para os traços semânticos dos nomes, de acordo com os dados analisados, o pronome quem, na relativa livre, aponta para um referente marcado pelos traços semânticos [+ANIMADO], [+HUMANO], [+/-DEFINIDO], [+/-GENÉRICO].

Os traços [+ANIMADO] e [+HUMANO] justificam-se pelo fato de que, em todas as ocorrências, o quem aponta para 'sujeitos humanos', sejam os possíveis interlocutores dos textos ou mesmo uma terceira pessoa que os escreventes mencionam. Já os traços [+/DEFINIDO] e [+/-GENÉRICO] apresentam uma possibilidade de variação: em algumas ocorrências, como em (5), (7) e (8), o pronome quem remete a um referente específico e/ou de identidade conhecida por um dos interlocutores ou por ambos; em outras, como em (4) e (6), esse vocábulo aponta para um referente de sentido genérico, cuja identidade não é conhecida por nenhum dos interactantes.

Na tabela 1, sintetizamos o quantitativo de ocorrências de referentes aos quais o pronome quem remete com base nos traços semânticos propostos por Chafe (1979).

Tabela 1 - Distribuição das ocorrências em função do referente do quem

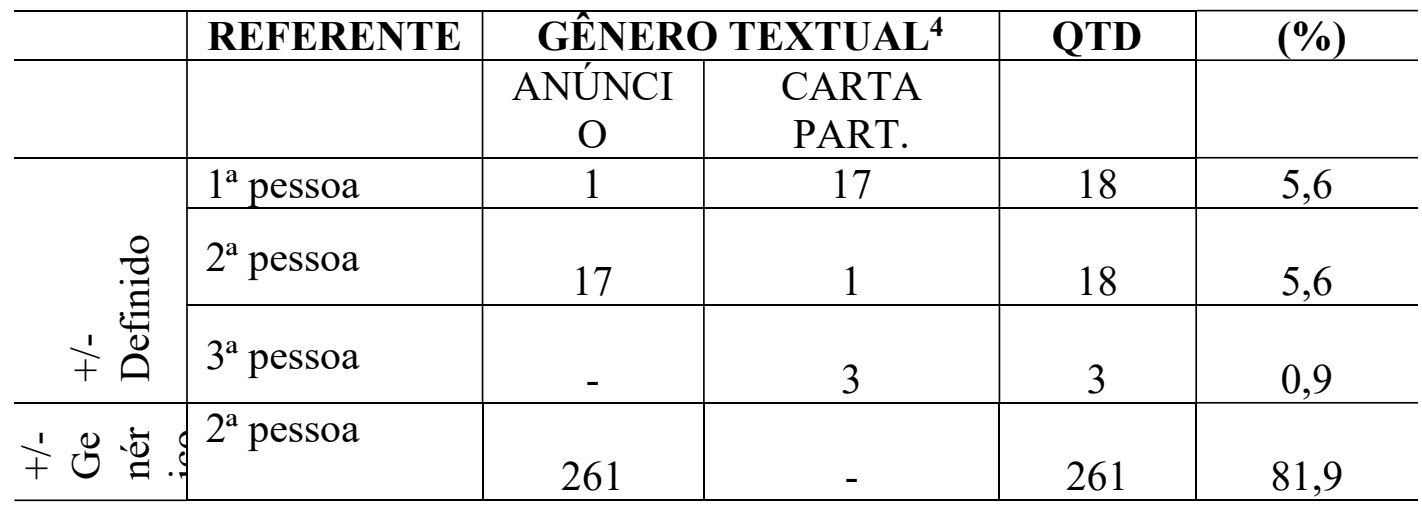

\footnotetext{
${ }^{4}$ Embora não seja nosso objetivo cotejar o comportamento das relativas livres nos anúncios e nas cartas particulares, optamos por separar as ocorrências por gênero textual para fins de clareza ao leitor. 


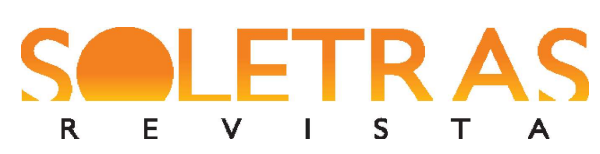

N. 41 - 2021.1 - EDVALDO BALDUINO BISPO

ALINE PRISCILLA ALBUQUERQUE BRAGA

\begin{tabular}{c|c|c|c|c|c}
\hline & $3^{\text {a }}$ pessoa & 2 & 17 & 19 & 6,0 \\
\hline & TOTAL & 281 & 38 & 319 & 100 \\
\hline
\end{tabular}

Fonte: Adaptado de Braga (2018)

A tabela 1 demonstra a distribuição dos dados em relação aos três referentes possíveis para o quem: primeira, segunda e terceira pessoas da enunciação, sendo mais frequente a segunda pessoa, com um somatório de 279 ocorrências (87,5\%). Esse quantitativo pode ser explicado pelo fato de, na maioria das amostras, o escrevente usar essa estrutura para referirse a seu(s) interlocutor(es).

Nos casos em que o quem se refere à segunda ou à terceira pessoa, vimos, com base na apresentação das ocorrências de (6) a (9), que os traços semânticos de definitude e genericidade podem variar. Nessa direção, os números constantes da tabela evidenciam ainda que esse pronome aponta, prototipicamente, para um referente cujo sentido é mais geral e, consequentemente, menos definido, com 280 dados (87,9\%). Esse resultado pode estar relacionado a dois fatores: à semântica de indefinição inerente ao pronome quem e ao fato de a maior parte dos dados ser proveniente dos anúncios que, diferentemente das cartas pessoais, não são direcionados a uma pessoa em específico.

Outros aspectos considerados na caracterização funcional de nosso objeto de estudo foram os tipos semânticos de verbos que ocorrem na relativa e na oração matriz, bem como os papéis semânticos atribuídos ao quem por esses verbos.

Tomando como referência a tipologia semântica estabelecida por Chafe (1979) e Borba (1996, 2002) para os verbos, as ocorrências (9) e (10), exemplificam tipos semânticos de verbo que o predicador da relativa livre pode exibir.

(9) Quem tiver escravos para vender de| boa figura e ainda moços, dirija-se á| Loja de Bastos Camelier \& Companhia, á rua| do Commercio número 12. (Corpus PHPB, anúncio de jornal, século XIX)

(10) No dia 1o. do corrente mez fugio da cidade de Marianna uma escrava de nome Thereza, $[. .$.$] Quem a capturar e avizar nesta typographia recebera'$ alviçaras. (Corpus PHPB, anúncio de jornal, século XIX)

As ocorrências destacadas em (9) e em (10) mostram alguns dos tipos semânticos de verbo que podem figurar no predicador da relativa livre. Assim, na oração em (9), o verbo ter, 


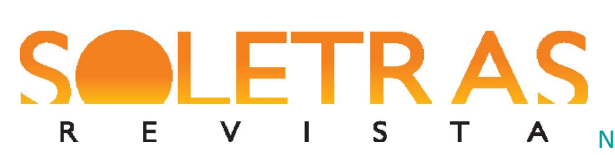

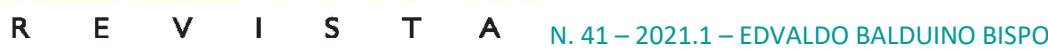

ALINE PRISCILLA ALBUQUERQUE BRAGA

que predica a relativa "quem tiver escravos para vender de boa figura e ainda moços", corresponde a um verbo de estado. A amostra em (10), por sua vez, exemplifica um caso de relativas livres coordenadas entre si, cujos verbos são de natureza semântica distinta: açãoprocesso (capturar) e ação (avisar). Na situação retratada, a ação codificada pela oração matriz (recebera' alviçaras) depende tanto de o leitor capturar a escrava fugida quanto de avisar na referida tipografia.

Vejamos, na tabela a seguir, a distribuição das ocorrências quanto ao tipo semântico de verbo da relativa livre.

Tabela 2 - Distribuição das ocorrências quanto ao tipo semântico de verbo da relativa livre

\begin{tabular}{c|c|c|c|c}
\hline $\begin{array}{c}\text { TIPO SEMÂNTICO } \\
\text { DO VERBO }\end{array}$ & \multicolumn{2}{|c|}{ GÊNERO TEXTUAL } & QTD & (\%) \\
\hline Estado & ANÚNCIO & CARTA PART. & & \\
\hline Ação-processo & 162 & 20 & 182 & 57,1 \\
\hline Processo & 78 & 6 & 84 & 26,3 \\
\hline Ação & 22 & 1 & 23 & 7,2 \\
\hline Processo/Estado & 11 & 11 & 22 & 6,9 \\
\hline Estado/Ação-processo & 5 & - & 5 & 1,6 \\
\hline Ação-processo/Ação & 2 & - & 2 & 0,6 \\
\hline TOTAL & 281 & - & 1 & 0,3 \\
\hline
\end{tabular}

Fonte: Braga (2018)

De acordo com a tabela 2, podemos notar que não há restrição quanto ao tipo semântico do predicador da relativa livre, considerando a proposta de Chafe (1979) e Borba (1996, 2002). Desse modo, os dados demonstram que aparecem os quatro tipos semânticos de verbos propostos pelos autores, sendo mais frequente o verbo de estado, com 182 ocorrências (57,1\%). Além disso, ocorrem também tipos semânticos de verbos distintos em um mesmo dado pelo mecanismo de coordenação oracional, ilustrado em (10), somando apenas 8 casos: ação-processo e estado, 7 ocorrências (2,2\%); processo e ação, com 1 ocorrência (0,3\%).

No que concerne aos papéis semânticos que o quem pode assumir em relação ao verbo da relativa livre, a análise do corpus demonstrou que esse pronome pode exercer cinco papéis distintos, considerando as propostas de Fillmore (1971 apud CASTILHO, 2012) e de Borba (1996, 2002). Vejamos (11) e (12): 


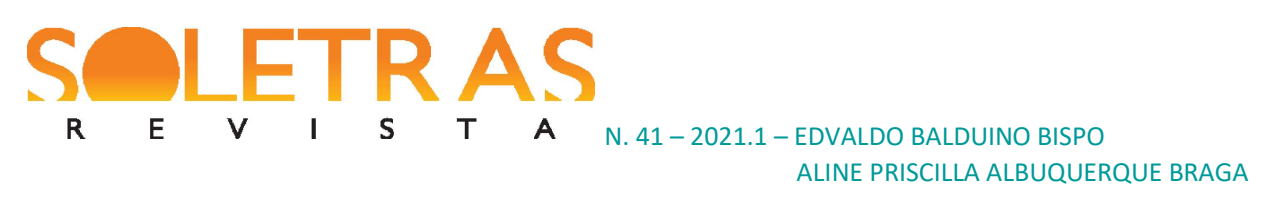

(11) [...] Quem| desejar uma boa afinação de piano| por $\mathbf{5 \$ 0 0 0}$ pòde derigir suas ordens para a casa do senhor Manoel tertulia|no de Almeida, á rua Formosa número 44. (Corpus PHPB, anúncio de jornal, século XIX)

(12) Ao Coronel José Pedro Galvão há mais de| anno fugio-lhe uma preta de nação, de nome Maria, [...] quem d'ella tiver noticias e va levar a seu| Senhor receberá alviçaras [...] (Corpus PHPB, anúncio de jornal, século XIX)

A relativa destacada em (11) mostra um caso do pronome quem associado a um verbo de estado, desejar, exercendo o papel semântico de experienciador. No dado (12), o elemento quem aparece relacionado ao verbo de estado ter e, coordenado a ele, aparece o complexo ir levar, com verbo pleno de ação-processo (levar). Nessa amostra, o quem exerce tanto o papel de suporte de propriedades (nesse caso, ter notícias de uma escrava fugida) quanto de agente (levar notícias da escrava fugida ao conhecimento de seu respectivo senhor, no caso).

Na tabela 3, sintetizamos, quantitativamente, a distribuição das ocorrências do corpus quanto ao papel semântico do quem atribuído pelo verbo da relativa livre.

Tabela 3 - Distribuição das ocorrências quanto ao papel semântico de quem atribuído pelo

\begin{tabular}{c|c|c|r|r}
\hline \multicolumn{5}{c}{ verbo da relativa } \\
$\begin{array}{c}\text { PAPEL } \\
\text { SEMÂNTICO }\end{array}$ & ANÚNCIO & CARTA PART. & & QTD \\
\hline Experienciador & 127 & 11 & 138 & 43,3 \\
\hline Agente & 90 & 16 & 106 & 33,2 \\
\hline Suporte & 56 & 8 & 64 & 20,0 \\
\hline Beneficiário & 1 & 3 & 4 & 1,3 \\
\hline Suporte e Experienciador & 5 & - & 5 & 1,6 \\
\hline Suporte e Agente & 2 & - & 2 & 0,6 \\
\hline TOTAL & 281 & 38 & 319 & 100,00 \\
\hline
\end{tabular}

Fonte: Braga (2018)

Conforme demonstrado na tabela 3 , o pronome quem pode exercer quatro tipos de papéis semânticos distintos, sendo o mais frequente deles o de experienciador, que corresponde a 138 ocorrências (43,3\%). Nos anúncios de jornal, houve acúmulo dos papéis de suporte e experienciador em 5 dados $(1,6 \%)$ e de suporte e agente em 2 dados $(0,6 \%)$. 


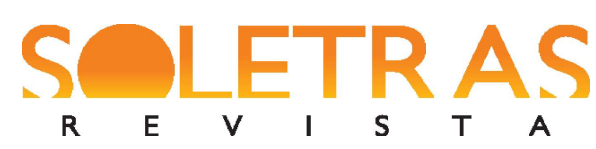

$\begin{array}{lllllllll}\mathbf{R} & \mathbf{E} & \mathbf{V} & \mathbf{I} & \mathbf{S} & \mathbf{T} & \mathbf{A} & \mathrm{N} .41-2021.1 \text {-EDVALDO BALDUINO BISPO }\end{array}$

ALINE PRISCILLA ALBUQUERQUE BRAGA

Com relação aos tipos semânticos do predicador da oração matriz, o levantamento dos dados revelou também não haver restrição a nenhum dos quatro tipos de verbos propostos por Chafe (1979) e Borba $(1996,2002)$, conforme demonstrado na tabela $4^{5}$.

Tabela 4 - Distribuição das ocorrências quanto ao tipo semântico de verbo da oração matriz

\begin{tabular}{l|c|c|r|r}
\hline $\begin{array}{c}\text { TIPO SEMÂNTICO } \\
\text { DO VERBO }\end{array}$ & \multicolumn{2}{|c|}{ GÊNERO TEXTUAL } & QTD & (\%) \\
\hline & ANÚNCIO & CARTA PART. & & \\
\hline Ação & 189 & 16 & 205 & 66,8 \\
\hline Processo & 13 & - & 13 & 4,2 \\
\hline Ação-processo & 70 & 6 & 76 & 24,8 \\
\hline Estado & 5 & 8 & 13 & 4,2 \\
\hline TOTAL & 277 & 30 & 307 & 100,00 \\
\hline
\end{tabular}

Fonte: Braga (2018)

Como podemos observar na tabela 4 , o tipo semântico de verbo mais frequente na oração matriz é o de ação, com um total de 205 ocorrências (66,8\%), seguido do verbo de ação-processo, com 76 dados (24,8\%). Esses quantitativos se assemelham, por um lado, a achados de pesquisas sobre outras estruturas oracionais, como Furtado da Cunha (2011), Lucena (2011), Furtado da Cunha e Bispo (2012), quanto aos dois tipos semânticos de verbos mais frequentes. Por outro lado, os dados desta pesquisa guardam particularidade quanto ao fato de os verbos de ação serem mais frequentes que os de ação-processo. Isso provavelmente se deve à natureza do complexo oracional tomado para amostra, que envolve relativa livre introduzida por quem, além do conteúdo e propósitos comunicativos dos textos em que a maioria dessas estruturas ocorreu: anúncios de jornais, nos quais se indicava a atitude, uma ação por parte dos possíveis interlocutores.

Em relação aos papéis semânticos atribuídos ao quem pelo predicador da oração matriz, encontramos a seguinte realidade, quantificada na tabela 5.

\footnotetext{
${ }^{5}$ Para a análise do tipo semântico do predicador da oração matriz e do papel semântico do quem atribuído por esse predicador, foram excluídos os dados em que a relativa livre assume uma função sintática em relação a um nome, como em "Confio que me considerará sempre no rol daqueles[...] que são dedicados aos bons sentimentos de quem tanto tem se esforçado sem outro enteresse a cauza publica senão o [seo]| engrandecimento" (Corpus PHPB, carta particular, século XIX). Com isso, foram excluídas 12 ocorrências. Resulta daí que a totalização dos quantitativos das tabelas 4 e 5 difere do total das tabelas anteriores.
} 


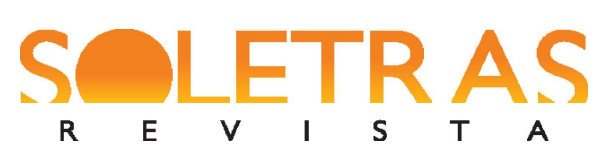

$\begin{array}{lllllllll}\mathbf{R} & \mathbf{E} & \mathbf{V} & \mathbf{I} & \mathbf{S} & \mathbf{T} & \mathbf{A} & \mathrm{N} .41-2021.1 \text {-EDVALDO BALDUINO BISPO }\end{array}$

ALINE PRISCILLA ALBUQUERQUE BRAGA

Tabela 5 - Distribuição das ocorrências quanto ao papel semântico do quem atribuído pelo

\begin{tabular}{|c|c|c|c|c|}
\hline \multirow{2}{*}{$\begin{array}{c}\text { PAPEL } \\
\text { SEMÂNTICO }\end{array}$} & \multicolumn{2}{|c|}{ GÊNERO TEXTUAL } & \multirow[t]{2}{*}{ QTD } & \multirow{2}{*}{$\begin{array}{c}\text { PORC } \\
(\%)\end{array}$} \\
\hline & ANÚNCIO & CARTA PART. & & \\
\hline Agente & 177 & 5 & 182 & 59,3 \\
\hline Beneficiário & 77 & 6 & 83 & 27,0 \\
\hline Alvo & 23 & 2 & 25 & 8,1 \\
\hline Paciente & - & 9 & 9 & 3,0 \\
\hline Suporte & - & 8 & 8 & 2,6 \\
\hline TOTAL & 277 & 30 & 307 & 100 \\
\hline
\end{tabular}

Fonte: Braga (2018)

A tabela 5 revela que o pronome quem pode assumir, em relação ao verbo da matriz, cinco papéis semânticos distintos, sendo predominante o papel de agente, com 182 ocorrências $(59,3 \%)$. Essa predominância deve-se ao fato de, na maioria dos casos, o pronome quem estar relacionado a um verbo de ação, conforme exposto na tabela 4. Vejamos esta amostra:

(13) [...]Hoje| é sexta feira, e segundo a folhinha| amanhãn deve ser sabbado, dia| em que por estylo vem quem| pode. [...] (Corpus PHPB, carta particular, século XIX)

A ocorrência em (13) ilustra a combinação mais recorrente no corpus: o predicador da matriz representado por um verbo de ação (nesse caso, vir) e o papel semântico de agente atribuído ao quem por esse verbo.

Também consideramos a atuação do princípio de iconicidade em ocorrências de estruturas sintáticas com a relativa livre introduzida por quem, tomando por base seus três subprincípios, nos moldes givonianos. Atentemos para a amostra em (14).

(14) A Tristão Cardoso de Menezes Branco mo-|rador no destricto de Curitiba vindo a Villa da Ati-|baia a seu negocio lhe fugio um escravo crioulo de| nome Generoso no dia 28 de Fevereiro [...] quem o prender entregará nesta Cidade| a Antonio Nunes Ramalho, no po[s]to de Jaguariaiba a Joaquim Matheus Branco, em Santo Antonio da| Lapa a Manoel Antonio da Cunha, e em qualqur| destas partes será recompensado [...]. (Corpus PHPB, anúncio de jornal, século XIX) 


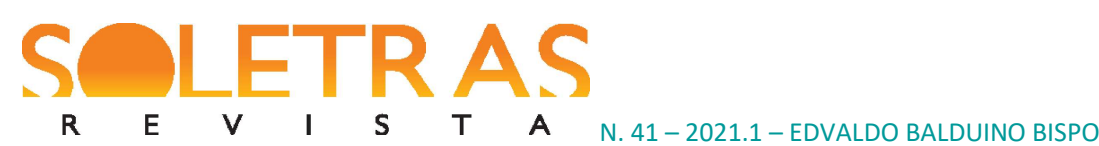

O conteúdo da relativa livre quem o prender equivale, do ponto de vista semânticoproposicional, ao de uma relativa com antecedente do tipo aquele(a)/qualquer um(a) que o prender, esta última opção com uma estrutura mais extensa. Contudo, a escolha por uma configuração oracional mais econômica estruturalmente, como a relativa livre, pode estar relacionada a um menor detalhamento que o anunciante intenciona dar à informação veiculada (menos conteúdo, portanto), conforme prevê o subprincípio da quantidade. Esse menor detalhamento liga-se diretamente aos objetivos comunicativos do anunciante e ao público genérico a que o anúncio se destina (quem quer que prenda o escravo).

Em termos do subprincípio da proximidade, em (14), o verbo da relativa livre (prender) apresenta-se formalmente integrado ao predicador da oração matriz (entregar), pela ausência de material linguístico entre eles. A essa maior integração no plano da forma pode subjazer uma integração também no plano do conteúdo, motivada pela intenção comunicativa de que a ação exposta na segunda oração seja executada tão logo a codificada pela primeira ocorra, considerando que o propósito comunicativo do anúncio em que ela está inserida é a captura de escravos fugidos.

Podemos perceber, ainda, a atuação do subprincípio da ordenação linear nos períodos complexos em que figuram as relativas livres introduzidas por quem sob dois aspectos: i) a posição da relativa em relação à matriz como reflexo da sequência cronológica em que os eventos por elas codificados ocorrem; ii) a ordenação dessas orações reflete o grau de importância que se quer atribuir a uma determinada porção de informação.

Sobre o primeiro aspecto, a ordenação da relativa em relação à oração matriz, na ocorrência em (14), reflete a sequência cronológica esperada para que os eventos por elas codificados ocorram: primeiro alguém prenderá o escravo fugido e, somente depois, será recompensado. A disposição escolhida pelo anunciante torna o anúncio transparente em relação à sequência das ações e, consequentemente, mais claro ao entendimento do leitor, aumentando as chances de que as ações pretendidas sejam realizadas.

Quanto ao segundo ponto, atentemos para o dado destacado em (15).

(15)Fugiram ao abaixo assignado, da sua fa-|zenda das Piteiras em Mogy-mirim, na noite|de 18 para 19 do corrente mez, dois escravos [...] Á quem os apprehender se gratificará com| $50 \$ 000$ réis por cada um. (Corpus PHPB, anúncio de jornal, século XIX) 


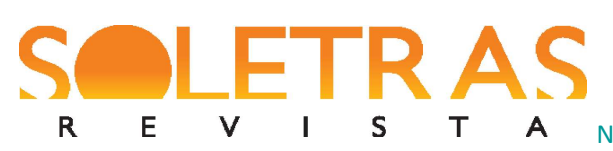

R $\quad$ E I S T T A N 41-2021.1-EDVALDO BALDUINO BISPO

A ocorrência em (15) apresenta uma relativa livre que exerce a função sintática de objeto indireto em uma posição não canônica para o $\mathrm{PB}$, visto que, prototipicamente, os termos que representam essa função, quando não pronominais, costumam aparecer pospostos ao verbo com o qual se relacionam.

De acordo com Givón (2001 p. 270), "uma fatia de informação mais importante é colocada na frente". Assim, em (15), a topicalização da relativa livre pode ilustrar a atuação do subprincípio da ordenação linear, na medida em que essa configuração formal pode ser indício de uma maior relevância discursiva dada àquele que prestará o serviço solicitado (prender os escravos fugidos) como tentativa de melhor persuadir os leitores do anúncio a aderir à busca e à apreensão dos escravos.

\section{Fatores sociointeracionais da relativa livre introduzida por quem}

Sabendo que, para uma análise centrada no uso, os aspectos discursivo-pragmáticos são imprescindíveis à constituição dos padrões linguísticos, o foco desta seção recai sobre os processos sociointeracionais, a exemplo das noções de (inter)subjetividade, inferência sugerida e os mecanismos de polidez e preservação das faces, os quais atuam na recorrência à relativa livre no corpus investigado.

Conforme discutido na seção que trata dos aspectos semânticos do tipo oracional em tela, atestamos que o pronome quem aponta para um referente com traços [+ANIMADO], [+HUMANO], [+/-DEFINIDO], [+/-GENÉRICO] que pode corresponder a qualquer uma das três pessoas envolvidas na enunciação. Quando se refere à primeira ou à segunda pessoas, em específico, a análise do corpus demonstrou a influência de fatores de natureza pragmática, em algumas ocorrências, como as noções de subjetividade e de intersubjetividade. Observemos (16) e (17).

(16) COLCHAS| De todas as cores. Não há quem tenha melhor sortimento| LOJA DO CARLOS (Corpus PHPB, anúncio de jornal, século XIX)

(17) São Gonçalo das Moças|| As suas festas estão correndo animadíssimos| lá pelos lados do Bomfim [...] Representa na primeira fila dos promoto-|res dellas a Popular Loja $1^{\circ}$ de Se-|tembro. E por isso, resolveu o seu proprie|tario, que, sem 


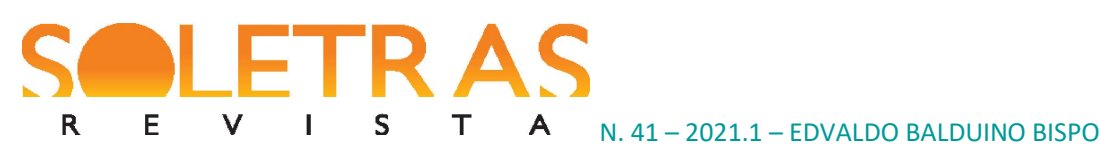

ALINE PRISCILLA ALBUQUERQUE BRAGA

deixar de ser amigo de $\mathrm{s} \mid$ mesmo, é de todos os seus bons freguezes-| fazer vendas baratissimas para que moço nem| moça, rapaz nem rapariga, tarugo nem taruga| alguma deixe de comparecer nos sobreditos| festejos [...] E, portanto, chegue quem quer fazer figura:| ha alfaiate e ha modista: ha fazendas e ha fi-|gurinos [...] (Corpus PHPB, anúncio de jornal, século XIX)

O dado negritado em (16) foi retirado de um anúncio de jornal relativo à venda de produtos. Nele, podemos constatar a manifestação da subjetividade do anunciante quando utiliza a oração "não há quem tenha melhor sortimento" para fazer um julgamento acerca de si mesmo. Nesse caso, ele usa essa estrutura, possivelmente, para demonstrar ao leitor ser o estabelecimento que possui a maior variedade de colchas e, assim, persuadi-lo a comprar em sua loja.

Com base na ocorrência em (17), também retirada de um anúncio de jornal, podemos atestar a expressão de intersubjetividade pelo autor. $\mathrm{Na}$ amostra, o anunciante alude ao desejo de seu leitor ir bem arrumado (fazer figura) a uma festa, por meio da oração "quem quer fazer figura". Com o uso da relativa livre, nesse caso, o escrevente manifesta seu julgamento sobre uma vontade que ele espera que os seus possíveis leitores apresentem e, desse modo, busca agir sobre eles, possivelmente, como uma tentativa de convencê-los a comprar roupas de festa na loja $1^{\circ}$ de Setembro.

Ainda no âmbito dos aspectos de natureza sociointeracional que podem estar relacionados ao uso da relativa livre introduzida por quem, a análise do corpus demonstrou a atuação da inferência sugerida em algumas ocorrências retiradas dos textos analisados. Consideremos a amostra destacada em (18).

(18) Sei, que se está reimprimindo| n'essa capital a importante| obra do Coronel I. Accioli de| Cerqueira e Silva - "Memorias| Historicas da Bahia"| [...] Sabe com que interesse| acompanho tudo quanto| é relativo á nossa Bahia.| Queira mandar suas| ordens á quem com parti=|cular apreço se honra em| ser| Seo Amigo. (Corpus PHPB, carta particular)

Conforme atestamos na seção destinada às propriedades semânticas do objeto em foco, em $87,9 \%$ dos dados, o pronome quem é usado para fazer menção a um referente de natureza genérica e não definida. A ocorrência destacada em (18), no entanto, exemplifica um uso não prototípico para esse elemento, visto que o escrevente utiliza a oração "á quem com 


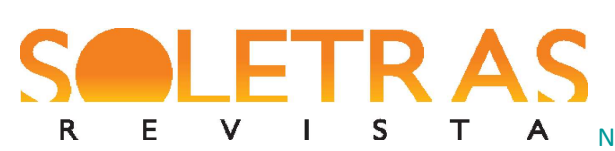

$\begin{array}{llllllll}\mathbf{R} & \mathbf{E} & \mathbf{V} & \mathbf{I} & \mathbf{S} & \mathbf{T} & \mathbf{A} & \mathrm{N} .41-2021.1 \text {-EDVALDO BALDUINO BISPO }\end{array}$

ALINE PRISCILLA ALBUQUERQUE BRAGA

parti=|cular apreço se honra em $\mid$ ser $\mid$ Seo Amigo", para referir-se a si mesmo e não a um referente desconhecido como a semântica de indefinição inerente ao pronome quem poderia sugerir.

Nessa amostra, o mecanismo de inferência sugerida se instaura por meio do uso da relativa livre na medida o autor da carta lança uma implicatura (recruta uma estrutura de acepção convencionalmente genérica e não definida para designar um referente cuja identidade é conhecida: o próprio remetente) e conta com a colaboração do destinatário para inferir a acepção diferente dada a essa estrutura, ou seja, a remissão a uma entidade conhecida pelos parceiros da interação.

À ocorrência destacada em (18) também subjaz outro aspecto de natureza sociointeracional: as estratégias de polidez e de preservação das faces. Essas noções configuram-se como mecanismos de que os interlocutores se valem para garantir uma boa interação, principalmente quando manifestam atos de fala potencialmente ameaçadores à manutenção de suas faces, como ordens ou pedidos, que, por sua natureza, pressionam o ouvinte, de alguma maneira, a atendê-los ou a rejeitá-los. De acordo com Brown e Levinson (1987), uma das maneiras de minimizar os efeitos de um ato que possa ameaçar a face do ouvinte é a manifestação de deferência por parte do falante e a impessoalização de um dos interactantes.

Nessa perspectiva, em (18), o autor da carta pede ao destinatário um determinado favor e, ao despedir-se, refere-se a si mesmo como "quem com particular apreço se honra em ser Seo Amigo". O uso do quem, nesse dado, confere um aparente distanciamento na maneira de expressar a característica que o remetente possui (ser amigo do destinatário, nesse caso), em virtude do sentido de indefinição convencionalmente atribuído a esse pronome. A recorrência à relativa livre, nesse caso, pode estar relacionada a uma estratégia do escrevente para aumentar as chances de ter seu pedido atendido por parte do destinatário da carta.

\section{Considerações finais}

Com base em pressupostos da Linguística Funcional, investigamos o uso da relativa livre introduzida por quem em dados do PB do século XIX. Focalizamos fatores semânticos, 


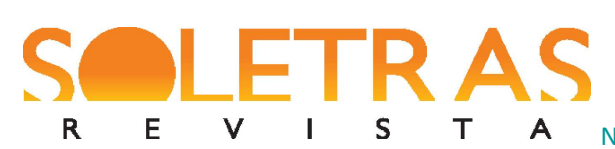

$\begin{array}{llllllll}\mathbf{R} & \mathbf{E} & \mathbf{V} & \mathbf{I} & \mathbf{S} & \mathbf{T} & \mathbf{A} & \mathrm{N} .41-2021.1-\text { EDVALDO BALDUINO BISPO }\end{array}$

semântico-cognitivo e sociointeracionais envolvidos em tais usos. A análise empreendida permitiu-nos constatar evidências do postulado funcionalista básico de que a forma da língua subordina-se às funções a que ela serve nas práticas interacionais.

No que concerne às propriedades semânticas, atestamos que o pronome quem aponta para um referente caracterizado pelos traços semânticos [+ANIMADO], [+HUMANO], [+/DEFINIDO], [+/-GENÉRICO], nos termos defendidos por Chafe (1979). Verificamos ainda não haver restrição a nenhum dos quatro tipos semânticos de verbos, propostos por Chafe (1979) e Borba $(1996,2002)$, para ocupar o lugar de predicador da relativa livre e da cláusula em que ela se encaixa. Constatamos, também, uma variedade de papéis semânticos que o pronome quem pode assumir, tanto em relação ao verbo da relativa quanto ao da matriz: agente, experienciador, suporte e beneficiário.

Em termos do princípio de iconicidade, pudemos observar uma relação motivada entre forma e função da oração relativa introduzida por quem, seja no que diz respeito à sua codificação morfossintática, sem a vinculação a um elemento nominal antecedente, seja no que tange à sua posição em relação à oração matriz.

Quanto aos fatores sociointeracionais relacionadas ao objeto em estudo, atestamos a atuação da subjetividade, da intersubjetividade, da inferência pragmática e das estratégias de polidez e preservação das faces. Nessa direção, aferimos aspectos (inter)subjetivos implicados em instâncias de uso da relativa livre em termos de julgamentos que os escreventes fazem de si mesmos e de seus interlocutores, bem como de monitoramento da atenção do interlocutor e de sua orientação a determinadas atitudes.

Outros processos interacionais cuja atuação também pudemos identificar foi a inferência sugerida, sobretudo voltada à semântica de definição/não genericidade atribuída ao pronome quem; e as estratégias de polidez e de preservação das faces, visto que, em alguns usos da relativa livre aqui estudada, os falantes conferiam um caráter atenuante a atos de fala que poderiam ameaçar a manutenção da face positiva dos interlocutores, por parecerem impositivos.

Destacamos, por fim, que os achados aqui explicitados, conquanto decorram da análise de um específico de dados, revelam tendências de uso das relativas livres introduzidas por quem em termos semânticos, cognitivos e interacionais. 


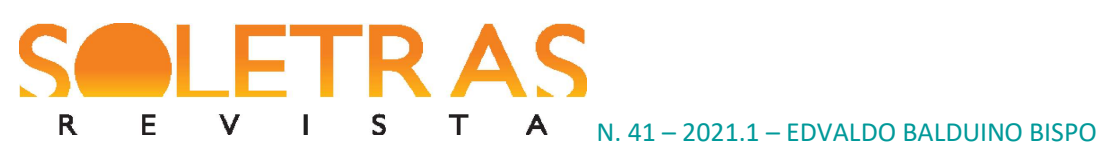

ALINE PRISCILLA ALBUQUERQUE BRAGA

\section{Referências}

BECHARA, E. C. Moderna Gramática Portuguesa. 37 ed. Rio de Janeiro: Nova Fronteira, 2009.

BISPO, E. B. Estratégias de relativização no português brasileiro e implicações para o ensino: o caso das cortadoras. 2009. 164f. Tese (Doutorado em Estudos da Linguagem) Universidade Federal do Rio Grande do Norte, Natal, 2009.

. Quem cala consente: abordagem funcional-construcionista de relativas sem antecedente introduzidas por 'quem'. Gragoatá, Niterói, v. 25, n. 52, p. 601-626, 2020.Disponível em: https://doi.org/10.22409/gragoata.v25i52.40823. Acesso em: 29 out. 2020.

.Relativa restritiva em perspectiva construcional. Entrepalavras, Fortaleza, v. 8, n. esp., p. 28-44, 2018. ISSN: 2237-6321. Disponível em: http://dx.doi.org/10.22168/223763216esp1200. Acesso em: 5 fev. 2020.

; FURTADO DA CUNHA, M. A. A subordinação adjetiva. In: CASTILHO, A. T. de (Org.). História do Português Brasileiro, vol. 5 - Mudança sintática das construções: perspectiva funcionalista. São Paulo: Contexto, 2019, p. 132-169.

; SILVA, J. R. Aspectos (inter)subjetivos no uso de sufixos graduadores nominais. In: SEMINÁRIO INTERNACIONAL DO GRUPO DE ESTUDOS DISCURSO \& GRAMÁTICA, 17, 2012. Anais [...] Natal-RN: EDUFRN, 2013, p. 80-90.

; OLIVEIRA, M. R. Orações relativas no português brasileiro: diferentes perspectivas. Niterói-RJ: EDUFF, 2014.

; SANTOS, L. T. Fatores semânticos, sociointeracionais e cognitivos da construção modalizadora com 'ficar de + infinitivo'. Revista Odisséia, v. 4, n. especial, p. 111-131, 2019.

BORBA, F. S. Uma gramática de valências do português. São Paulo: Ática, 1996.

. Dicionário de usos do Português do Brasil. São Paulo: Ática, 2002.

BRAGA, A. P. de A. Relativa livre introduzida por quem: uma interpretação funcionalista. 2018. 130f. Dissertação (Mestrado em Estudos da Linguagem) - Universidade Federal do Rio Grande do Norte, Natal-RN, 2018.

BRITO, A. M. B. de. A sintaxe das orações relativas em português. Porto: Correio do Minho, 1988.

BROWN, P.; LEVINSON, S. Politeness: some universals in language usage. Cambridge: Cambridge University Press, 1987.

BYBEE, J. Language, usage and cognition. Cambridge: CUP, 2010.

CANÇADO, M. Manual de semântica: noções básicas e exercícios. Belo Horizonte: Ed. UFMG, 2005. 


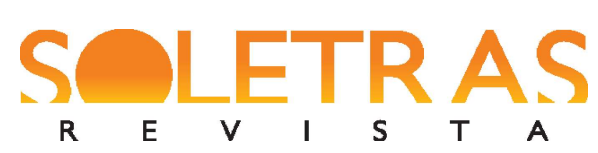

$\begin{array}{llllll}\mathbf{R} & \mathbf{V} & \mathbf{T} & \mathbf{A} & \text { N. 41-2021.1-EDVALDO BALDUINO BISPO }\end{array}$

CASTILHO, A. T. de. Nova gramática do português brasileiro. São Paulo: Contexto, 2012.

CHAFE, W. Significado e estrutura linguística. Rio de Janeiro: Ao Livro Técnico, 1979.

CROFT, W. Radical construction grammar: syntactic theory in typological perspective. Oxford: Oxford University Press, 2001.

CUNHA LACERDA, P. F. do A. O papel do método misto na análise de processos de mudança em uma abordagem construcional: reflexões e propostas. Revista LinguíStica, Rio de Janeiro, n. especial, p. 83-101, 2016.

FURTADO DA CUNHA, M. A. A construção transitiva no português do Brasil. In: Congreso de la ALFAL, 16, 2011, Alcalá de Henares. Actas del XVI Congreso de la ALFAL. Alcalá de Henares: Universidad de Alcalá, 2011, p. 1-10.

; BISPO, E. B. Relações sintático-semânticas da oração. In: PALOMANES, R. M.; BRAVIN, A. M. Práticas de ensino de português. São Paulo: Contexto, 2012, p. 143-164.

; BISPO, E. B.; SILVA, J. R. Linguística Funcional Centrada no Uso: conceitos básicos e categorias analíticas. In: CEZÁRIO, M. M.; FURTADO DA CUNHA, M. A. (orgs.). Linguística Funcional Centrada no Uso: uma homenagem a Mario Martelotta. Rio de Janeiro/Cataguases-MG: FAPERJ/Mauad, 2013, p. 13-36.

; COSTA, M. A.; CEZARIO, M. M. Pressupostos teóricos fundamentais. In:

OLIVEIRA, M. R.; MARTELOTTA, M. E. (Orgs.) Linguística funcional: teoria e prática. São Paulo: Parábola Editorial, 2015, p. 21-47.

GIVÓN, T. On understanding grammar. New York: Academic Press, 1979.

Syntax: a functional-typological introduction. Amsterdam: John Benjamins, 1984.

Funcionalism and grammar. Amsterdam/Philadelphia: John Benjamins, 1995.

Syntax - an introduction. v. 1. Amsterdam /Philadelphia: J. Benjamins, 2001.

GOFFMAN, E. A elaboração da face. Uma análise dos elementos rituais na interação social. In: FIGUEIRA, S. (Org.). Psicanálise e Ciências Sociais. Rio de Janeiro: Francisco Alves, 1973.

HOPPER, P. J. Emergent grammar. In: Berkeley Linguistics Society, v. 13, p. 139-157, 1987.

JOHNSON, R. B.; ONWUEGBUZIE, A. J.; TURNER, L. A. Toward a definition of mixed methods research. Journal of Mixed Methods Research, Surrey, UK, n. 1. p. 112-133, 2007.

KEENAN, E. L. Relative Clauses. In: SHOPEN, T. Language, typology and syntactic description, v. II: Complex Constructions. Cambridge: Cambridge University Press, 1985, p. 141-170.

LAKATOS, E. M.; MARCONI, M. de A. Metodologia do trabalho cientifico. 7 ed. rev. e ampl. São Paulo: Atlas, 2010.

LAKOFF, G.; JOHNSON, M. Metáforas da vida cotidiana. Campinas, SP: Mercado das Letras, 2002. 


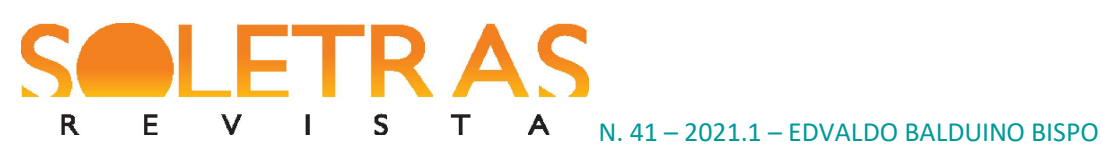

ALINE PRISCILLA ALBUQUERQUE BRAGA

LANGACKER, R. W. Foundations of Cognitive Grammar. California: Stanford University Press, 1987.

LUCENA, N. L. Relação gramatical objeto direto: a interface entre sintaxe, semântica e pragmática. Letrônica, Porto Alegre, v. 4, n. 2, p. 12-30, 2011.

MARCHESAN, A. C. As relativas livres em português brasileiro e os requerimentos de compatibilidade. 99f. Dissertação (Mestrado em Linguística) - Universidade Federal de Santa Catarina, Florianópolis, 2008.

. As relativas livres no português brasileiro. 227f. Tese (Doutorado em Linguística) Universidade Federal de Santa Catarina, Florianópolis, 2012.

MARCUSCHI, L. A. Marcadores conversacionais no português brasileiro: formas, posições e funções. In.: CASTILHO, A. T. de (org.). Português culto falado no Brasil. Campinas: Editora UNICAMP, 1989.

MARTELOTTA, M. E. Mudança linguística: uma abordagem centrada no uso. São Paulo: Cortez, 2011.

MEDEIROS JUNIOR, P. Sobre Sintagmas-QU e Relativas Livres no Português. Dissertação (Mestrado em Linguística) - Universidade de Brasília, Brasília, 2005.

Relativas Livres do PB: Sintaxe, Semântica e Diacronia. Tese (Doutorado em Linguística) - Universidade Estadual de Campinas, Campinas, 2014.

MÓIA, T. A. Sintaxe das orações relativas sem antecedente expresso do português. $163 \mathrm{f}$. Dissertação (Mestrado em Letras) - Universidade de Lisboa, Lisboa, 1992.

ROCHA LIMA, C. H. da. Gramática Normativa da Língua Portuguesa [1972]. 40 ed. Rio de janeiro: José Olympio, 2001.

SCHIFFRIN, D. Discourse markers. Cambridge: Cambridge University Press, 1987.

.The management of a co-operative self during argument: The role of opinions and stories. In: GRIMSHAW, Allen D. (Ed.). Conflict talk: sociolinguistic investigations of arguments in conversations. Cambridge: Cambridge University Press, 1990, p. 241-259

SILVA, C. R. de O. Metodologia e organização do projeto de pesquisa (Guia prático). Fortaleza-CE: Centro Federal de Educação Tecnológica do Ceará, 2004.

TAYLOR, J. R. Syntactic construction as prototype categories. In: The new psicology of language: cognitive and functional approaches to language structure. New Jersey: Lawrence Erlbaum, 1998.

THOMPSON, S. A.; COUPER-KUHLEN, E. The clause as locus of grammar and interaction. Discourse studies, v. 7, n. 4-5, p. 481-506, 2005.

TOMASELLO, M. The new psicology of language: cognitive and functional approaches to language structure. New Jersey: Lawrence Erlbaum, 1998.

TRAUGOTT, E. C.; DASHER, R. B. Regularity in semantic change. Cambridge: CUP, 2002. 


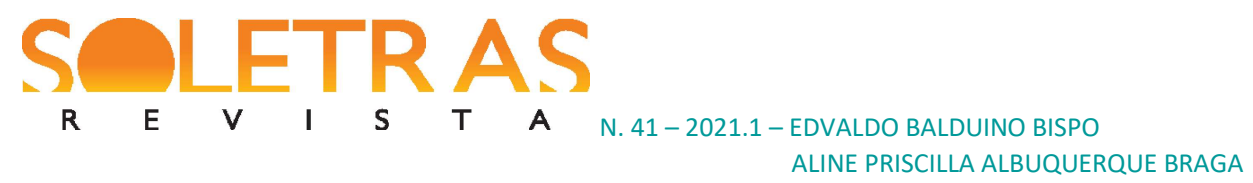

\section{Functional properties of headless relative introduced by who}

Abstract: In this paper, we investigate functional aspects (semantic, semantic-cognitive and sociointeractional) involved in the use of headless relative clause introduced by quem (who) in Brazilian Portuguese (PB). This study is supported theoretically by Functional Linguistics, according to Givón (1984, 1995), Martelotta (2011), Furtado da Cunha and Bispo (2013), Furtado Cunha, Oliveira and Martelotta (2015). It is a qualitative and quantitative research. Our database are newspaper ads and private letters produced in the 19th century, from the corpora Projeto História do Português Brasileiro (PHPB). The results shows that (i) the pronoun quem (who) points to a referent characterized by the semantic features [+ ANIMATED], [+ HUMAN], [+/-DEFINED] and [+/- GENERIC]; (ii) there is no restriction on the semantic types of verb that can predicate the headless relative clause and the main clause; (iii) the pronoun quem (who) can play various semantic roles; (iv) socio-interactional aspects, such as subjectivity, intersubjectivity and invited inference, motivate the use of headless relative clause in the analyzed data.

Keywords: Functional aspects. Headless relative clauses. Functional Linguistics.

Recebido em: 19 de novembro de 2020.

Aceito em: 15 de dezembro de 2020. 